\title{
UMA PROPOSTA DE ALINHAMENTO DAS ÁREAS DE PESQUISA EM UM PROGRAMA DE PÓS-GRADUAÇÃO EM ENGENHARIA DE PRODUÇÃO
}

\author{
C. F. Nunes ${ }^{1}$; A. D. Weise ${ }^{1}$; F. S. B. Medeiros ${ }^{1 *}$ \\ 1 Universidade Federal de Santa Maria. 97105-900, Santa Maria, RS - Brasil \\ * flaviani.13@gmail
}

Artigo submetido em 03/08/2015 e aceito em 25/08/2015

\section{RESUMO}

Considerando as práticas de organização e financiamento da pós-graduação stricto sensu existentes na Alemanha este artigo pretende elaborar uma proposta de alinhamento das áreas de pesquisas que o Programa de Pós-graduação em Engenharia de Produção da Universidade Federal de Santa Maria/RS (PPGEP-UFSM) pode adotar a fim de estimular as indústrias regionais a financiar pesquisas no curso. Para tanto, foram analisadas 29 empresas que fazem parte da região do Conselho Regional de Desenvolvimento e tem Santa Maria/RS como município sede. Os dados foram coletados junto ao Cadastro Industrial da Federação das Indústrias do Estado do Rio Grande do Sul, Fundação de Economia e
Estatística e no Instituto Brasileiro de Geografia e Estatística. Para adotar um modelo de financiamento da pós-graduação semelhante ao praticado na Alemanha, recomenda-se que o PPGEP-UFSM busque uma maior afinidade entre suas linhas de pesquisa e as atividades produtivas das indústrias regionais. Sugere-se que o programa desenvolva pesquisas em maquinário compatível com o produzido na região para a produção de tecnologias de produção de alimentos e também para a melhoria do manejo e beneficiamento de grãos e carnes, possibilitando assim, às indústrias locais uma melhoria das condições de competitividade.

PALAVRAS-CHAVE: pós-graduação, linhas de pesquisa, engenharia de produção.

\section{AN ALIGNMENT OF THE PROPOSED RESEARCH AREAS IN A POST GRADUATE PROGRAM IN INDUSTRIAL ENGINEERING}

\begin{abstract}
Considering the organizational practices and financing of strict post-graduate studies existing in Germany this article intends to prepare an alignment proposal in the areas of research that the Postgraduate Program in Industrial Engineering from the Federal University of Santa Maria/RS (PPGEP-UFSM) can adopt to stimulate regional industries to fund research on the course. Therefore, they analyzed 29 companies that are part of the Regional Development Council region and has Santa Maria/RS as county seat. Data were collected by the Registry of the Industrial Federation of Industries of Rio Grande do Sul State, Economy and Statistics Foundation
\end{abstract}

and the Brazilian Institute of Geography and Statistics. To adopt a graduate of the financing model similar to that practiced in Germany, it is recommended that the PPGEP-UFSM seek greater affinity between their lines of research and production activities of regional industries. It is suggested that the program develops research in machinery compatible with that produced in the region for the production of food production technologies and also to improve the handling and processing of grain and meat, thus enabling local industries an improvement in conditions competitiveness.

KEYWORDS: post graduation, research lines, industrial engineering. 


\section{INTRODUÇÃO}

O desenvolvimento econômico dos países tem estado estreitamente relacionado ao investimento feito por eles em seu capital humano. E em todos os níveis a educação é uma condição altamente influente no desempenho econômico ainda que não seja suficiente para sozinha ditar-lhe os resultados. A qualidade da educação e a maneira como ela é distribuída são também aspectos de grande relevância (LÓPEZ; THOMAS; WANG, 1998).

Conforme Chaves e Araújo (2011), o processo de expansão da educação superior brasileira está diretamente ligado a um incremento da inserção do Brasil no mercado internacional e a um movimento reformista orientado por organismos multilaterais de financiamento, como o Fundo Monetário Internacional e o Banco Mundial como forma de condicionamento à obtenção de recursos das mais diversas ordens.

No segmento acadêmico e científico da Engenharia, acompanhando a evolução da ciência e da tecnologia, são muitas áreas do conhecimento que vêm crescendo no Brasil, sendo a maioria delas reconhecidas pelo Conselho Regional de Engenharia e Agronomia e pelo Conselho Regional de Administração e objeto de cursos reconhecidos pela Coordenação de Aperfeiçoamento de Pessoal de Nível Superior (CAPES).

Entretanto, nas últimas décadas, o Brasil diminuiu os investimentos na formação de engenheiros bem qualificados, enquanto outras nações investiram maciçamente na formação de seu corpo de engenheiros e de seus próprios modelos de desenvolvimento de tecnologia (AMORIN, 2009). Por isso, observar como outras nações vêm gerindo seu custeio da produção de tecnologia, a exemplo da Alemanha, pode proporcionar ao Brasil o conhecimento necessário para elevar de forma sustentável seus investimentos na formação de sistemas de educação e pesquisa de alto nível, favorecendo o desenvolvimento da capacidade produtiva do país e à sua competitividade no cenário internacional.

Diante do exposto, este artigo tem como objetivo elaborar uma proposta de alinhamento das áreas de pesquisas que o Programa de Pós-graduação em Engenharia de Produção da Universidade Federal de Santa Maria/RS (PPGEP-UFSM) pode adotar a fim de estimular as indústrias regionais a financiar pesquisas no curso.

Este trabalho é relevante considerando a importância da formação de pessoal na área de Engenharia de Produção para o Brasil e a necessidade de aumentar o nível e a qualidade dos profissionais dessa área no país. Como também levando em conta que a elevação do número de pesquisadores acadêmicos demanda recursos que impactam substancialmente sobre o orçamento da União. Assim, pretende-se verificar as possibilidades de alinhamento das áreas de pesquisa que o PPGEP-UFSM pode trazer a sua realidade econômica e regional a luz do que acontece nos programas de pós-graduação na Alemanha e, assim, estimular as indústrias regionais a financiar pesquisas no curso.

O presente artigo está estruturado da seguinte forma: imediatamente após a introdução, consta o referencial teórico que embasou esse estudo contemplando itens como o financiamento da pós-graduação na Alemanha, e também, o financiamento da pós-graduação no Brasil. Na sequência, visualizam-se os materiais e métodos adotados na pesquisa. Logo após, segue os resultados e discussão. E por fim encontra-se exposto a conclusão a partir do estudo realizado.

\section{REFERENCIAL TEÓRICO}

Esta seção foi desenvolvida com o objetivo de embasar teoricamente os assuntos a serem desenvolvidos no decorrer deste estudo. Deste modo, a seguir, apresentam-se discussões acerca do 
financiamento da pós-graduação na Alemanha, em seguida, a respeito do financiamento da pósgraduação no Brasil.

\subsection{O financiamento da pós-graduação na Alemanha}

Neste trabalho, toma-se a Alemanha como país que tem um modelo de financiamento da pós-graduação diferente do modelo brasileiro, de modo a proporcionar subsídios sobre alternativas do financiamento da pós-graduação e da pesquisa no Brasil. A Alemanha é também um dos países do mundo que mais formam doutores anualmente. O país ostenta a taxa de 15,4 doutores por mil habitantes (Centro de Gestão e Estudos Estratégicos, 2010), o que a coloca atrás apenas da Suíça que tem ampla vantagem sobre os outros países.

De acordo com o Federal Ministry of Education and Research (Alemanha, 2011), a Alemanha possui uma rede única de instituições de pesquisa universitária e extra-universitária que trabalha em estreita cooperação com a indústria e o comércio. Os laços entre a ciência e a indústria estão se fortalecendo substancialmente, o que deverá garantir o êxito da Alemanha no mercado global.

Fundamentalmente, as instituições de pesquisa diferem umas das outras quanto ao tipo de pesquisa (básica/aplicada) e ao modo de financiamento (público/privado). Sendo assim, a Figura 1 a seguir ilustra o esquema do modelo alemão de organização e financiamento da pós-graduação.

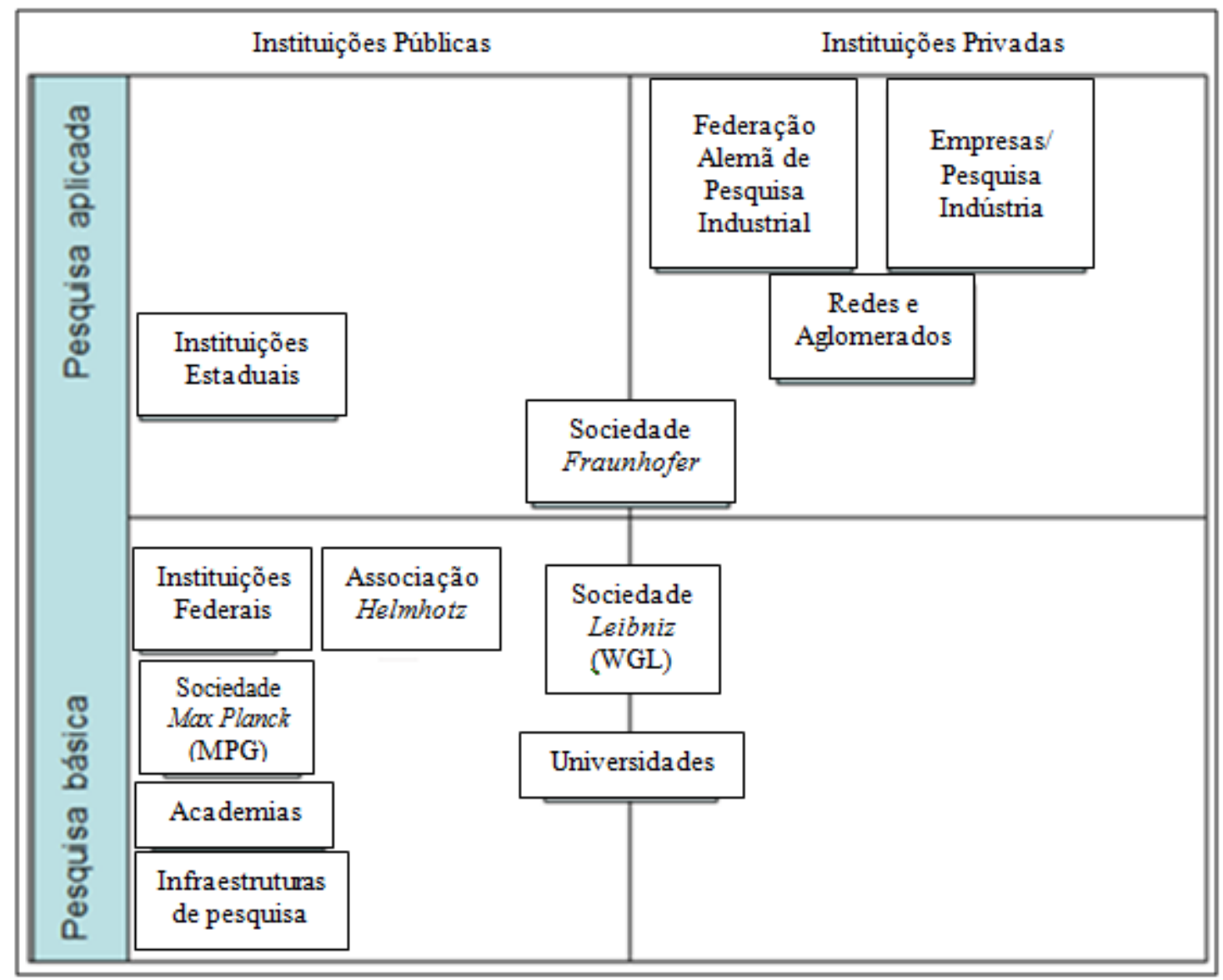

Figura 1 - Modelo alemão organização e financiamento pós-graduação.

Fonte: Adaptado Alemanha (2011). 
Conforme se pode perceber através da análise da Figura 1, as instituições de pesquisa estão diferenciadas umas das outras em relação aos tipos de pesquisa e também em relação a seu tipo de financiamento. Além disso, observa-se que na Alemanha os locais de pesquisa são diversificados, sendo estas realizadas em universidades, escolas superiores de ciências aplicadas, institutos extrauniversitários federais e estaduais e em empresas.

No país há, aproximadamente, 750 instituições de pesquisa com financiamento público além de centros de pesquisa e desenvolvimento operados por grupos industriais (ALEMANHA, 2011). Em áreas ou regiões selecionadas, essas instituições industriais e acadêmicas agrupam as suas atividades de pesquisa e desenvolvimento formando redes e aglomerados, os chamados "cluster".

É possível afirmar que na Alemanha existe uma dinâmica através da qual as indústrias financiam instituições de pesquisa e essas instituições, em reciprocidade, promovem pesquisas que são do interesse dessas indústrias.

Um exemplo do modelo de financiamento da pesquisa de pós-graduação alemã é o caso da Sociedade Fraunhofer, maior instituição de pesquisa aplicada na Europa. A instituição desenvolve pesquisas sob encomenda dos setores públicos, industriais ou de prestação de serviços (EMBAIXADA E CONSULADOS GERAIS DA ALEMANHA NO BRASIL, 2010). Com este modelo de financiamento à pesquisa a Alemanha chegou ao final de 2009 à posição de terceira maior produtora de artigos científicos, com aproximadamente 90 mil artigos produzidos por ano (BRASIL, 2012).

\subsection{O financiamento da pós-graduação no Brasil}

De acordo com o Censo da Educação Superior divulgado pelo Ministério da Educação (2010), no corrente ano o Brasil apresentava 173.408 alunos em cursos de pós-graduação, sendo 144.911 matriculados em instituições públicas e 28.497 em instituições privadas (Tabela 1).

Tabela 1 - Censo da Educação Superior - 2010

\begin{tabular}{|c|c|c|c|c|c|c|}
\hline \multirow{3}{*}{$\begin{array}{l}\text { ESTATÍSTICAS } \\
\text { BÁSICAS }\end{array}$} & \multicolumn{6}{|c|}{$\begin{array}{l}\text { Dados da pós-graduação no Brasil } \\
\text { CATEGORIA ADMINISTRATIVA }\end{array}$} \\
\hline & \multirow{2}{*}{$\begin{array}{l}\text { TOTAL } \\
\text { GERAL }\end{array}$} & \multicolumn{4}{|c|}{ PÚBLICA } & \multirow[b]{2}{*}{ PRIVADA } \\
\hline & & Total & Federal & Estadual & Municipal & \\
\hline $\begin{array}{l}\text { Matrículas de pós- } \\
\text { graduação }\end{array}$ & 173.408 & 144.911 & 95.113 & 48.950 & 848 & 28.497 \\
\hline
\end{tabular}

Fonte: Ministério da Educação do Brasil/INEP (2011).

O financiamento da pós-graduação no Brasil tem como principal agente a CAPES, que investe anualmente cerca de $\mathrm{R} \$ 1,2$ bilhão para programas de bolsas, programas de fomento, portal de periódicos e programas indutivos e especiais, dentro da sistemática de apoio à pós-graduação (BRASIL, 2013).

Existem outros mecanismos de apoio na CAPES, como no caso das bolsas para o exterior, de doutorado sanduíche, doutorado pleno e pós-doutorado. Há, ainda, programas de intercâmbio da pós-graduação direcionado às universidades brasileiras que estabelecem cooperação com universidades de vários lugares do mundo (BRASIL, 2013).

Além do orçamento da CAPES, segundo Schwartzman (2010), no Brasil os recursos para a pós-graduação podem provir de diferentes fontes que investem na pesquisa, tais como: o Conselho Nacional de Desenvolvimento Científico e Tecnológico (CNPq), Fundos Setoriais, Financiadora de Estudos e Projetos (FINEP) e o próprio Ministério da Ciência e Tecnologia além do Ministério da 
Educação (MEC) que garante a permanência de professores doutores em tempo integral para atividades de pesquisa.

De acordo com Brasil (2010), os dados sobre o financiamento da pós-graduação no país indicam que seu maior investidor é o Governo Federal, seguido em menor escala pelos estados, sendo a contribuição de outros atores apenas discreta, não obstante já sejam significativos os investimentos globais em pesquisa e desenvolvimento dos setores produtivos não governamentais.

É importante destacar que, na década de 1990, o Brasil vinha praticando uma generosa política de distribuiç̧ão de bolsas de estudos para seus pós-graduandos, todavia, na década de 2000 houve uma elevação no número de alunos que pressionou para baixo o percentual de bolsas (VELHO, 2007). Por isso, Neves (2012) entende que o crescimento da pós-graduação pressupõe uma adequada equação do financiamento, tendo em vista que o sistema público de bolsas não será suficiente para dar conta de atender contingentes cada vez maiores de alunos, e sem um adequado suporte aos estudantes a qualidade do sistema tende a ser comprometida.

Sob esse enfoque, Rapini (2007) cita que nos países em desenvolvimento ainda se percebem baixos níveis de articulação entre as universidades e as empresas, porém, existe uma gradual reversão desse quadro, e embora que de forma lenta, fluxos bilaterais de conhecimentos e técnicas vêm se desenhando no Brasil.

\section{MATERIAIS E MÉTODOS}

Com o propósito de alcançar o objetivo definido neste trabalho, em um primeiro momento, adotou-se uma pesquisa documental e bibliográfica quanto aos meios de investigação, e num segundo momento, uma pesquisa do tipo exploratória, descritiva, bem como aplicada quanto aos fins utilizados (VERGARA, 2014).

Deste modo, foram envolvidas no estudo 29 empresas que fazem parte do segmento de indústrias de bens de produção e de bens de consumo que possuíam mais de 50 colaboradores. Esta delimitação foi arbitrada pelos autores em face da necessidade que empresas com mais colaboradores têm para serem mais produtivas, competitivas e sustentáveis. Foram excluídas da investigação as micro empresas industriais, que segundo a classificação do Serviço de Apoio às Micro e Pequenas Empresas (SEBRAE, 2013), contam com até 18 colaboradores, e também as pequenas empresas que empregam menos de 50 funcionários.

As 29 empresas analisadas fazem parte da região do Conselho Regional de Desenvolvimento (Corede Central) e tem Santa Maria/RS como município sede. A coleta dos dados foi realizada no mês de março de 2013 através de consultas a fontes documentais como o Cadastro Industrial da Federação das Indústrias do Estado do Rio Grande do Sul (FIERGS, 2012). Foram consultados ainda sítios eletrônicos oficiais da Fundação de Economia e Estatística (FEE, 2012) e do Instituto Brasileiro de Geografia e Estatística (IBGE, 2012).

Os dados que constituem o objeto de interesse desta investigação são referentes aos perfis das indústrias que operam na região Central do Estado do Rio Grande do Sul onde se situa a Universidade Federal de Santa Maria/RS. De tal maneira a observar possíveis linhas de pesquisa para o PPGEP-UFSM caso se voltasse para investigações que se propusessem a apoiar o trabalho das indústrias locais. Sendo assim, buscou-se conhecer o que as indústrias locais produzem a fim de identificar oportunidades de parceria no desenvolvimento de pesquisas em âmbito local.

No caso, verificar que tipos de tecnologias lhes podem ser úteis visando inferir que tipo de pesquisas o PPGEP-UFSM deve desenvolver para ser proativo em relação a essas organizações e obter delas interesse em financiar pesquisas acadêmicas em uma parceria benéfica às empresas e à 
sociedade através do Programa tal como acontece nas parcerias entre universidades e empresas na Alemanha. Os dados coletados foram sistematizados com o auxílio do software Microsoft Excel $^{\circledR}$.

\section{RESULTADOS E DISCUSSÃO}

Neste capítulo serão apresentados os resultados da pesquisa. Sendo assim, primeiramente, segue exposta a produção industrial de Santa Maria/RS e região contemplando as indústrias de bens de produção. Em seguida, consta a produção industrial de Santa Maria/RS e região, porém, agora considerando as indústrias de bens de consumo. E por último, apresenta-se uma proposta de alinhamento das áreas de pesquisa para a realidade econômica da região.

\subsection{A produção industrial de Santa Maria/RS e região: indústrias de bens de produção}

As indústrias de bens de produção são aquelas que transformam matérias-primas da natureza fornecendo materiais, máquinas e energia para o abastecimento de outras indústrias (MENEZES; RAMOS, 2006). No entendimento de Mendonça (2011), as indústrias de bens de produção - ou indústrias de base - tendem a se localizar perto de fontes fornecedoras ou de portos e ferrovias, o que facilita a recepção de matérias-primas e o escoamento da produção. Essas condições estão parcialmente presentes em Santa Maria/RS que faz uso da malha ferroviária estadual para receber e enviar mercadorias. Em Santa Maria/RS e região do Corede Central existem 10 indústrias de bens de produção com mais de 50 colaboradores, sendo que 9 localizam-se no município de Santa Maria/RS e 1 em Itaara/RS. Metade dessas indústrias existentes são de máquinas e implementos agrícolas (3 indústrias) e as outras 2 são de equipamentos elétricos.

De acordo com o Cadastro Industrial da FIERGS (2012), as indústrias de máquinas e equipamentos são em maior número, representadas por três empresas com mais de 50 colaboradores no setor, são elas: S.R. Engenharia; Thor Máquinas e Montagens e Agrimec Máquinas e Montagens. Essas organizações produzem diversos produtos de natureza mecânica, mas têm foco em máquinas e equipamentos para a agricultura e a pecuária. Também entre seus principais produtos estão o projeto, a fabricação, a montagem e a assistência técnica de equipamentos industriais, estruturas metálicas e elevadores de passageiros. A Thor produz ainda máquinas para a indústria do fumo e máquinas frigoríficas.

No setor de equipamentos elétricos, a região conta com duas indústrias - a Pólo e a Pólo Electro - especializadas na produção de equipamentos de geração e distribuição de energia elétrica que somam 260 colaboradores envolvidos na fabricação de transformadores, indutores, conversores, sincronizadores e semelhantes, peças e acessórios.

Os outros segmentos da indústria de bens de produção têm um representante cada conforme pode ser visto no Gráfico 1. A Santa Fé Vagões S/A fabrica locomotivas e outros materiais rodantes e faz a manutenção e reparação de vagões de trens. Enquanto que a Sociedade Vicente Pallotti fabrica artefatos de cerâmica e barro cozido para uso na construção; a Brita Pinhal Indústria e Comércio extrai e promove a britagem de pedras e outros materiais para construção; a Seleta indústria e comércio de serviços de concretagem opera fabricando massa e argamassa para a construção civil e pesada. A Metalúrgica Cofelma fabrica e comercializa produtos de trefilados de metal. 


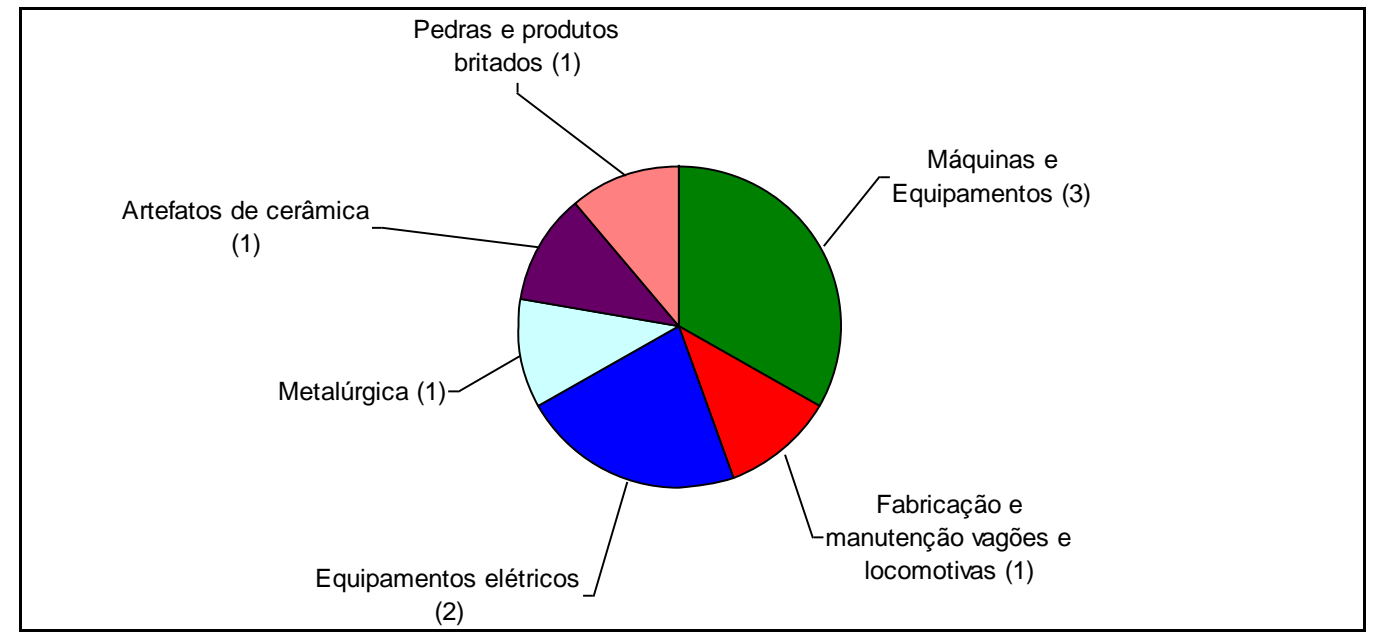

Gráfico 1 - Classificação e quantidade das indústrias locais de bens de produção Fonte: Dados da pesquisa.

De acordo com Neumann (2002), entre as indústrias brasileiras de máquinas agrícolas, em especial entre as pequenas, existem conceitos que são tipicamente inerentes ao escopo da Engenharia de Produção, como o Just in Time e o Programa 5S, capazes de promover a melhoria de processos produtivos que ainda são pouco explorados ou mesmo desconhecidos pelas pequenas indústrias de máquinas e implementos agrícolas. A produtividade nessas indústrias é diretamente relacionada à utilização de tecnologias adequadas e modernas (SILVA JUNIOR; NEUMANN, 2010).

No Brasil, esse tipo de indústria ligado ao setor de produção metal-mecânico e energético já vem estabelecendo parcerias com os sistemas acadêmicos em prol do desenvolvimento de pesquisas e novas tecnologias para o setor. Nesse sentido, em se tratando de uma atuação voltada para atender as indústrias de bens de produção de Santa Maria/RS e da região do Corede Central incluídas neste estudo, a pesquisa em Engenharia de Produção no PPGEP-UFSM vai atender aos interesses dessas organizações se produzir investigações na área de melhoria e inovações em máquinas e implementos agrícolas e no desenvolvimento de equipamentos e soluções para a fabricação de equipamentos de geração e distribuição de energia elétrica.

\subsection{A produção industrial de Santa Maria/RS e região: indústrias de bens de consumo}

De acordo com Paula (2011), as indústrias de bens de consumo são aquelas que produzem bens para o consumidor final: a população comum. Seus produtos subdividem-se em bens duráveis - para consumo a longo prazo - onde se incluem mercadorias não perecíveis como: automóveis, móveis, eletroeletrônicos, entre outros; e - em bens não duráveis - de primeira necessidade para consumo imediato como: alimentos, têxteis, vestuários, medicamentos, cosméticos, entre outros.

Santa Maria/RS possui 19 indústrias de bens de consumo com mais de 50 empregados. Destacam-se a CVI refrigerantes, com 529 colaboradores, e o Frigorífico Silva que emprega 500 pessoas na atividade de abate e comercialização de carnes bovinas (FIERGS, 2012). Entre as organizações de produzem bens de consumo na região em análise estão: (1) Antoniazzi e Cia Ltda.; (2) Pádua Ltda.; (3) Marzari Alimentos; (4) Corrieri Alimentos; (5) MK Metalúrgica Kirchoff; e (5) Idema Peças e Máquinas Agrícolas.

Vale salientar que essas empresas que operam na cidade de Santa Maria/RS e na região do Corede Central são consumidores em algum momento de produtos fornecidos por outras 
organizações que servem de insumos a seus processos produtivos, incluindo-se entre estas as empresas apontadas neste estudo. As indústrias de bens de consumo em operação na região são classificáveis conforme pode ser visualizado no Gráfico 2.

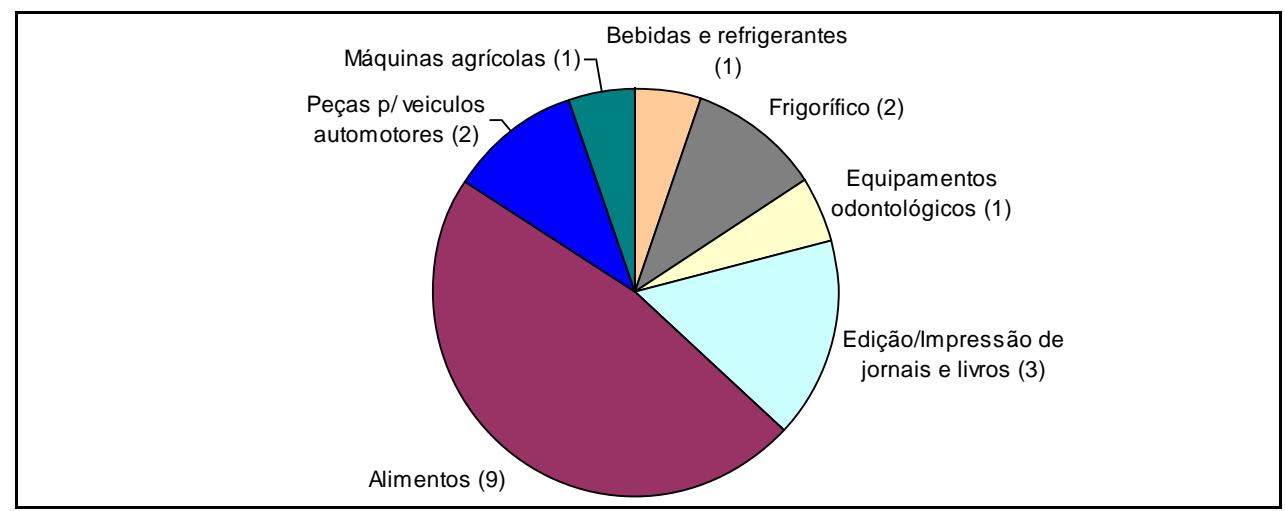

Gráfico 2 - Classificação e quantidade das indústrias locais de bens de consumo Fonte: Dados da pesquisa.

Notadamente, as indústrias de alimentos são as organizações em maior número, sendo que 04 operam em Santa Maria/RS; 03 em Agudo/RS; 01 em Júlio de Castilhos/RS; e 01 em Nova Palma/RS. Dentre essas indústrias, 04 operam com trigo e seus subprodutos como massas e biscoitos, são elas: Corrieri Alimentos e Antoniazzi e Cia ambas de Santa Maria/RS, com 100 e 182 colaboradores, respectivamente; Redol Alimentos de Agudo/RS; e Indústria Alimentícia Fadiole de Nova Palma/RS, com 60 funcionários cada uma.

Os municípios de Agudo/RS, Júlio de Castilhos/RS, Nova Palma/RS e Tupanciretã/RS têm, somados, 06 indústrias do segmento. Predominam entre essas indústrias o beneficiamento de grãos e a produção de alimentos como massas e biscoitos. As indústrias de edição e impressão de produtos impressos da região são três e funcionam em Santa Maria/RS. A Rede Brasil Sul de Televisão (RBS TV) representada pelo Zero Hora editora jornalística, a Empresa Jornalística De Grandi e Sociedade Vicente Pallotti empregam 99, 90 e 160 colaboradores, respectivamente.

A região conta ainda com 02 frigoríficos: o Frigorífico Silva de Santa Maria/RS, especializado no abate e comercialização de carne, couro e outros subprodutos de gado bovino e o Agropastoril de Tupanciretã/RS, que abate e comercializa produtos suínos e bovinos. Na região, levando em conta o critério de indústrias com mais de 50 colaboradores, as indústrias de bens de consumo são as que mais empregam. Tais indústrias requerem a utilização de um complexo aparato mecânico em seus processos, entre os quais existem os processos de limpeza automatizada de vasilhames, misturas, envasamento, embalagem, rolagem, entre outros.

Incluem-se entre essas indústrias a Pádua Ltda., a Marzari Alimentos e a Corrieri Alimentos Ltda. todas fabricantes de gêneros alimentícios no município de Santa Maria/RS. As indústrias Redol Alimentos Ltda., Indústria Alimentícia Fadiole e Agropastoril BS também enquadram-se nas mesmas características. No entanto, são dos municípios de Agudo/RS, Nova Palma/RS e Tupanciretã/RS, respectivamente, cidades estas que ficam no entorno de Santa Maria/RS.

No município de Santa Maria/RS se destacam ainda as empresas ligadas à metalurgia leve são elas: a MK Metalurgia, a Idema Peças para Máquinas Agrícolas e a ELK Indústria e Comércio de Autopeças. Essas indústrias, com média de 60 colaboradores cada, dedicam-se a fabricação de autopeças e acessórios para veículos automotores e equipamentos de transmissão. Além destas, a Metalúrgica Kirchhof Ltda. e a ELK Indústria e Comércio de Autopeças fabricam peças para veículos automotores, empregando cada uma delas 60 colaboradores. 
Os municípios de Agudo/RS e Júlio de Castilhos/RS possuem indústrias de beneficiamento de arroz e outros grãos que empregam, somadas, aproximadamente 500 pessoas. Essas organizações fazem uso de tecnologias específicas que utilizam técnicas inerentes às indústrias mecânicas e também relacionadas à logística e ao manejo de produtos agrícolas. Essas indústrias são: a Cotrijuc - Cooperativa Agropecuária de Júlio de Castilhos/RS, a Cooperativa Mista de Agudo/RS Ltda. e a Dickow e Cia Ltda. também localizada em Agudo/RS.

Uma parte dessas empresas faz uso não apenas de processos e equipamentos mecânicos como também de tecnologia de produção de alimentos em face da natureza de seus negócios. Além disso, como quaisquer outras empresas, fazem uso ainda de tecnologias de gestão.

Para que o PPGEP-UFSM atue de maneira que desencadeie o interesse das indústrias de bens de consumo regionais deve levar em conta que existe uma predominância das indústrias de alimentos em relação às outras indústrias, principalmente as que produzem subprodutos do trigo. Massas de diferentes tipos, biscoitos, bolachas, doces, entre outros, são gêneros alimentícios produzidos na região, em especial, nos municípios de Santa Maria/RS e Agudo/RS. Além disso, existe acentuada atividade de beneficiamento de grãos e expressiva atividade industrial sobre a carne bovina.

No contexto dos produtos alimentícios, as boas práticas de fabricação se tornaram uma das formas para atingir um alto padrão de qualidade na fabricação de gêneros alimentícios e incluem não apenas responsabilidade pelo produto fabricado, como também orienta mudanças na metodologia de produção, no projeto e no uso de equipamentos, instalações e aspectos relacionados ao sistema de gestão da produção, todos diretamente relacionados com o desenvolvimento de tecnologias e também pertencentes ao escopo de atuação da Engenharia de Produção (SILVA, 2004; NICOLOSO, 2010).

O Programa de Engenharia de Produção da UFSM pode orientar suas linhas de pesquisa no sentido de produzir e melhorar as tecnologias de produção de alimentos, não apenas para agregar mais qualidade à produção, mas também para desenvolver inovações que despertem o interesse do mercado consumidor.

Da mesma forma como acontece na Alemanha, a cooperação entre as instituições de pesquisa universitária, a indústria e o comércio pode resultar em pesquisas que alavanquem as inovações e o desenvolvimento industrial local na região central do Estado do Rio Grande do Sul. Por isso, o PPGEP-UFSM pode direcionar suas linhas de pesquisa de modo a agregar maiores benefícios tecnológicos às instituições produtivas regionais. Essa parceria com a indústria local pode beneficiar tanto as organizações por meio de inovações, como o próprio PPGEP-UFSM através de uma nova alternativa de financiamento de seu custeio.

\subsection{Proposta de alinhamento das áreas de pesquisa para a realidade econômica da região}

As universidades federais têm entre as suas atribuições a função de promover, por meio da capacitação dos cidadãos brasileiros, o desenvolvimento social e econômico através do ensino e da pesquisa científica, propiciando avanços e melhorias no padrão de conduta das pessoas e o desenvolvimento industrial e produtivo em geral.

$\mathrm{Na}$ indústria, em seus distintos subsetores, a pesquisa desenvolvida em parceria com as universidades pode promover redução de custos e aperfeiçoamento das cadeias produtivas, tornando-as mais competitivas e possibilitando um maior enriquecimento do país. A partir de tais proposições pode-se inferir que às universidades compete exercer o papel de estimuladoras do desenvolvimento e esse papel as universidades alemãs exercem junto às indústrias de suas regiões de atuação. 
Isto é, as universidades alemãs obtêm recursos para o financiamento de suas pesquisas ao promoverem o estudo e as inovações em benefício dessas indústrias, no caso elas alinham suas investigações com a realidade produtiva e econômica das regiões nas quais elas estão instaladas. Esse é um contexto em que se incluem pesquisas e atividades de produção das mais diversas áreas, mas que tem em comum a afinidade entre o que as universidades pesquisam e entre o que as indústrias produzem numa relação de interesses mútuos.

Por analogia, é possível afirmar que para que a pesquisa no PPGEP-UFSM esteja alinhada com a realidade produtiva regional ela poderá contemplar no segmento de pesquisas sobre bens de produção, as investigações voltadas para a geração de inovações e melhorias. Para tornar mais eficiente tal esforço de alinhamento, propõe-se que sejam incluídas disciplinas que ampliem e melhorem o potencial de capacitação e excelência no desenvolvimento, produção e manutenção de produtos inerentes à indústria metal-mecânica, como máquinas agrícolas, equipamentos industriais, elevadores, entre outros.

Nesses aspectos, incluem-se as disciplinas que fazem parte da subárea de Engenharia de Operações e Processos de Produção, tais como: Gestão de Sistemas de Produção e Operações; Planejamento, Programação e Controle da Produção; Gestão da Manutenção; Projeto de Fábrica e de Instalações Industriais: organização industrial, layout/arranjo físico; Processos Produtivos Discretos e Contínuos: procedimentos, métodos e sequências; Engenharia de Métodos.

A promoção do alinhamento com a realidade produtiva regional em relação aos bens de consumo requer que o referido programa de pós-graduação institua áreas de pesquisa voltadas à melhoria e as inovações em gestão e gerenciamento de processos de produtos alimentícios de maneira a possibilitar às indústrias existentes na região melhores recursos e tecnologias para tornarem-se mais produtivas e competitivas.

Nesse sentido, são compatíveis com essas necessidades as disciplinas relacionadas à Engenharia do Produto associadas ao desenvolvimento, organização, decisão e execução de atividades estratégicas e operacionais de desenvolvimento de novos produtos, envolvendo desde sua concepção até o lançamento. Tais disciplinas são: Gestão do Desenvolvimento de Produto; Processo de Desenvolvimento do Produto; Planejamento e Projeto do Produto.

\section{CONCLUSÃO}

Com a realização deste estudo constatou-se que no Brasil os modelos de financiamento da pós-graduação provêm de fonte pública - realizado por meio das universidades federais - e privadas - através de instituições particulares de ensino. No caso da Alemanha, o país demonstra uma alternativa para o financiamento da pós-graduação stricto sensu que pode ser adotada pelo PPGEPUFSM tanto em benefício do custeio do próprio Programa como em favor das indústrias sediadas na região de Santa Maria/RS.

Note-se que atuando de modo a interligar os avanços da ciência com o desempenho das indústrias essas parcerias na Alemanha contribuem com o desenvolvimento econômico e social daquele país. O financiamento da pesquisa acadêmica na Alemanha além de possibilitar o aumento de inovações tecnológicas e industriais alivia os custos do Estado e beneficia instituições e universidades com o recebimento de royalties de suas patentes inovadoras.

A respeito da região de Santa Maria/RS é possível observar que o número de organizações industriais de médio e grande porte é relativamente reduzido em comparação com outras regiões do Estado. Observa-se ainda que, a natureza da produção das indústrias é diversificada, mas que a fabricação de máquinas e implementos agroindustriais e de equipamentos para a geração e 
distribuição de energia elétrica são representativos das principais indústrias regionais de bens de produção. Ressalta-se também que a fabricação de gêneros alimentícios derivados do trigo, bem como os derivados da carne bovina e suína são atividades que adequadamente representam a indústria regional de bens de consumo.

Em vista disso, ao propor linhas de pesquisa que possibilitem ao PPGEP-UFSM maior produtividade em pesquisas ajustadas aos interesses das indústrias locais e/ou regionais, salienta-se a importância deste programa de pós-graduação aprofundar as afinidades de suas linhas de pesquisa com a realidade produtiva local. Para isso, passando a promover investigações relacionadas à produção metal-mecânica de máquinas e implementos agrícolas, de infraestrutura de geração e distribuição de energia elétrica, de desenvolvimento e melhoria de alimentos derivados de trigo, e ainda, de tecnologias de produção de alimentos produzidos com carnes de rebanhos bovinos e suínos.

Mais explicitamente, o PPGEP-UFSM poderá ser mais útil às indústrias da região se promover linhas de pesquisa que tenham identificação com os processos e os produtos que constituem a realidade dessas organizações. Dessa forma, poderá atender às necessidades de melhoria, inovação e competitividade das mais representativas empresas industriais de Santa Maria/RS e região, oportunizando agregar recursos através de parcerias com essas indústrias.

Além disso, o estabelecimento de parcerias mais estreitas com organizações produtivas locais pode ainda proporcionar mais experiências em campo proveitosas a docentes, discentes e empresas ao enriquecer a experiência formativa. É preciso, no entanto, salientar que o estreitamento das relações e eventuais financiamentos por parte da iniciativa privada não consubstancia uma privatização do ensino de alto nível, mas, o compartilhamento das oportunidades, das responsabilidades e dos benefícios entre a sociedade e o capital privado a exemplo do que vem sendo realizado na Alemanha.

Portanto, o exemplo de financiamento misto demonstrado neste trabalho pode ser adequado à realidade regional que contextualiza a atuação do PPGEP-UFSM como alternativa de financiamento das pesquisas do programa, desoneração dos encargos públicos e criação de uma cultura de estabelecimento de parcerias no desenvolvimento de inovações.

\section{REFERENCIAS}

ALEMANHA - Federal Ministry of Education and Research. O panorama da pesquisa na Alemanha: quem faz pesquisa na Alemanha? 2011. Governo da Alemanha. Disponível em: <http://www.research-ingermany.de/dachportal/en/downloads/download-files/70998/brochure-the-german-research-landscape-

portugiesisch.pdf>. Acesso em: 29 dez. 2012.

AMORIM, E. de S. Em defesa da engenharia: os grandes desafios da profissão no Brasil do século XXI. São Paulo: Instituto de Engenharia, 2009.

BRASIL - Ministério da Fazenda. Economia brasileira em perspectiva. Brasília: Ministério da Fazenda, 2012.

. Coordenação de Aperfeiçoamento de Pessoal de Nível Superior. Plano Nacional de Pós-Graduação - PNPG 2011-2020. v. II. Brasília: CAPES, 2010.

Financiadora de estudo e projetos. 2013. Disponível em: <http://www.finep.gov.br/pagina.asp?pag=programas_apresentação\#instituicao>. Acesso em: 19 fev. 2013.

CENTRO DE GESTÃO E ESTUDOS ESTRATÉGICOS. Doutores 2010: estudos da demografia da base técnicocientífica brasileira. Brasília: Centro de Gestão e Estudos Estratégicos, 2010.

CHAVES, V. L. J.; ARAÚJO, R. S. Política de expansão das universidades federais via contrato de gestão - uma análise da implantação do REUNI na Universidade Federal do Pará. Revista Universidade e Sociedade, Brasília, n. 48, p.11-17, 2011. 
EMBAIXADA E CONSULADOS GERAIS DA ALEMANHA NO BRASIL. Novas parcerias fortalecem inovação e crescimento. 2010.

Disponível

<http://www.brasil.diplo.de/Vertretung/brasilien/pt/01__Willkommen/Noticias_202010/Schavan_20no_20Brasil__Seit e.html>. Acesso em: 12 fev. 2013.

FEE - Fundação de Economia e Estatística. 2012. Disponível em: <http://dados.fee.tche.br/>. Acesso em: 10 abr. 2013.

FIERGS - Federação das Indústrias do Estado do Rio Grande do Sul. Cadastro das indústrias, fornecedores e serviços. Porto Alegre: FIERGS, 2012.

IBGE - Instituto Brasileiro de Geografia e Estatística. 2012. Disponível em: <http://www.ibge.gov.br/home/>. Acesso em: 15 maio 2013.

LÓPEZ, R.; THOMAS, V.; WANG, Y. Addressing the education puzzle: the distribution of education and economic reforms. The wold bank library. New York: The Wold Bank, 1998.

MENDONÇA, T. Introdução à geografia das indústrias. 2011. Apostila. Universidade Estadual do Vale do Acaraju. Disponível em: <http://www.tiberiogeo.com.br/texto/TextoUvaGeografiaIntroducaoIndustria.pdf> Acesso em: 08 abr. 2013.

MENEZES, M. B.; RAMOS, W. M (Orgs.). Proformação. Brasília: MEC. Secretaria de Educação Básica, 2006.

MINISTÉRIO DA EDUCAÇÃO. Censo da Educação Superior 2010. Divulgação dos principais resultados do Censo da Educação Superior. Brasília: MEC/INEP, 2011.

NEUMANN, C. S. R. Desenvolvimento de fornecedores: um estudo de caso no setor de máquinas agrícolas. $114 \mathrm{f}$. 2002. Dissertação (Mestrado em Engenharia de Produção) - Universidade Federal do Rio Grande do Sul, Porto Alegre, 2002.

NEVES, A. A. B. Transformações do ensino superior e a pesquisa no Brasil. Centro Alemão de Ciência e Inovação São Paulo. 2012. Disponível em: <http://www.dwih.com.br/fileadmin/user_upload/DialoguePDF/2._Abilio__Transformacoes_do_Ensino_Superior_e_a_Pesquisa_no_Brasil.pdf >. Acesso em: 23 abr. 2013.

NICOLOSO, T. F. Proposta de integração entre BPF, APPCC, PAS 200:2008, e a NBR ISO 22000:2006 para a indústria de alimentos. 70 f. 2010. Dissertação (Mestrado em Engenharia de Produção) - Universidade Federal de Santa Maria, Santa Maria, 2010.

PAULA, R. S. As empresas do Rio de Janeiro e o período de payback. 35 f. 2011. Monografia (Especialização em Finanças e Gestão Corporativa) - Universidade Candido Mendes, Rio de Janeiro, 2011.

RAPINI, M. S. Interação universidade-empresa no Brasil: evidências do Diretório dos Grupos de Pesquisa do CNPq. Estudos Econômicos, São Paulo, v. 37, n. 1, p. 211-233, 2007.

SCHWARTZMAN, J. Financiamento da pós-graduação no Brasil. In: Plano Nacional de Pós-Graduação (PNPG): 2011-2020. Documentos setoriais. v. II. Brasília: CAPES, 2010.

SEBRAE - Serviço de Apoio às Micros e Pequenas Empresas. Critérios de classificação das empresas: EI-ME-EPP. 2013. Disponível em: <http://www.sebrae-sc.com.br/leis/default.asp?vcdtexto=4154>. Acesso em: 14 abr. 2013.

SILVA JUNIOR. L. H.; NEUMANN, M. Determinantes das médias salariais dos trabalhadores da indústria de máquinas e implementos agrícolas no noroeste do Rio Grande do Sul. In: SOCIEDADE BRASILEIRA DE ECONOMIA, ADMINISTRAÇÃO E SOCIOLOGIA RURAL, 48., Campo Grande, 2010. Anais... Campo Grande: SOBER, 2010.

SILVA, A. F. F. Impactos da estratégia de diversificação na estratégia de produção: estudo de caso da empresa Vilma Alimentos. 133 f. 2004. Dissertação (Mestrado em Engenharia de Produção) - Universidade Federal de Minas Gerais, Belo Horizonte, 2004.

VELHO, L. O papel da formação de pesquisadores no sistema de inovação. Ciência e Cultura, São Paulo, v. 59, n. 4, p. 23-28, 2007.

VERGARA, S. C. Projetos e relatórios de pesquisa em Administração. 15. ed. São Paulo: Atlas, 2014. 